\title{
Interactions between a Top Order Predator and Exotic Mesopredators in the Australian Rangelands
}

\author{
Katherine E. Moseby, ${ }^{1,2}$ Heather Neilly, ${ }^{2}$ John L. Read, ${ }^{1,2}$ and Helen A. Crisp ${ }^{2}$ \\ ${ }^{1}$ School of Earth and Environmental Sciences, The University of Adelaide, SA 5005. Arid Recovery, P.O. Box 147, \\ Roxby Downs, South Australia 5725, Australia \\ ${ }^{2}$ Arid Recovery, P.O. Box 147, Roxby Downs, SA 5725, Australia
}

Correspondence should be addressed to Katherine E. Moseby, katherine.moseby@adelaide.edu.au

Received 4 August 2011; Accepted 27 September 2011

Academic Editor: Cajo J. F. ter Braak

Copyright (C) 2012 Katherine E. Moseby et al. This is an open access article distributed under the Creative Commons Attribution License, which permits unrestricted use, distribution, and reproduction in any medium, provided the original work is properly cited.

An increase in mesopredators caused by the removal of top-order predators can have significant implications for threatened wildlife. Recent evidence suggests that Australia's top-order predator, the dingo, may suppress the introduced cat and red fox. We tested this relationship by reintroducing 7 foxes and 6 feral cats into a $37 \mathrm{~km}^{2}$ fenced paddock in arid South Australia inhabited by a male and female dingo. GPS datalogger collars recorded locations of all experimental animals every 2 hours. Interactions between species, mortality rates, and postmortems were used to determine the mechanisms of any suppression. Dingoes killed all 7 foxes within 17 days of their introduction and no pre-death interactions were recorded. All 6 feral cats died between 20 and 103 days after release and dingoes were implicated in the deaths of at least 3 cats. Dingoes typically stayed with fox and cat carcasses for several hours after death and/or returned several times in ensuing days. There was no evidence of intraguild predation, interference competition was the dominant mechanism of suppression. Our results support anecdotal evidence that dingoes may suppress exotic mesopredators, particularly foxes. We outline further research required to determine if this suppression translates into a net benefit for threatened prey species.

\section{Introduction}

Introduced feral cats (Felis catus) and red foxes (Vulpes vulpes) have been implicated in the historical extinction and decline of many Australian mammal species [1-4] as well as the failure of several recent attempts to reintroduce threatened species to the wild [5-9]. Effective control of the red fox and feral cat is a core objective of many Australian mammal and terrestrial bird recovery programs. Although the red fox has been successfully controlled in some areas of Australia using poison meat baits [10], the efficacy of long-term baiting can attenuate due to high selection pressure for toler-ance to 1080 [11] and bait shyness attributable to receiving a sublethal dose of poison. Control of foxes is also thought to lead to an increase in cat density $[10,12,13]$ which could negate any positive biodiversity benefits. Poisoning feral cats is often ineffective owing to poor bait uptake [14-20] and a cost effective, large scale control mechanism for feral cats is currently not available [21].

Interspecific killing between carnivores is common [22], and recent studies have highlighted the possible role of toporder predators in controlling second-tier carnivores (mesopredators) [23-25]. The mesopredator release hypothesis predicts that reduced abundance of top-order predators results in increased abundance or activity of smaller subordinate predators [23]. This hypothesis has most support in North America, where studies have found that when coyote (Canis latrans) abundance declines, red fox numbers increase $[23,26]$. The removal of the grey wolf, Canis lupus, has also been linked to an increase in coyote populations [27], and the removal of coyotes has resulted in changes in bobcat ( $\operatorname{Lyn} x$ rufus) and gray fox (Urocyon cinereoargenteu) populations [28]. In Scandinavia, the pine marten (Martes martes) was found to increase after a decline in red fox populations [29]. 
Where predation efficiency or prey specificity of smaller predators is superior or different to that of the top-order predator then changes in prey abundance can result [23]. Glen and Dickman [24] outlined complex interactions between carnivores in Australia and suggested that mesopredator release is an important mechanism shaping current prey populations in Australia. The post-European extinction of some Australian mammal species is thought to at least be partly attributable to mesopredator release through the removal or control of the dingo (Canis lupus dingo) [4]. Stable dingo populations are still found in many arid areas of Australia and may provide a net benefit to some threatened wildlife species through a decrease in predation rates by the red fox and/or feral cat [2, 29-32]. Smith and Quin [2] found lower rates of conilurine rodent extinction in areas where dingoes were abundant, and Johnson et al. [4] has suggested that mammal extinctions and decline are less severe in areas where dingoes are still present. Letnic et al. $[33,34]$ also favour the mesopredator release hypothesis as well as the trophic cascade theory, which suggests that top predators such as dingoes have either positive or negative effects on lower trophic levels and may indirectly enhance plant biomass [35]. The removal of dingoes may thus allow herbivores [36] and smaller introduced predators to increase, depleting plant biomass and increasing predation pressure.

Unfortunately little empirical data exist to support the perceived role of the dingo in suppressing fox and cat abundance at landscape scales [37] with evidence relying on correlations using historical or observational data (see $[34,38]$ ). However, dingoes have been recorded occasionally killing or eating foxes [39] and cats [40,41], and remains of both have been recorded in dingo scats, although usually at a very low occurrence $[39,42-45]$. Dingoes are thought to exclude foxes from resource points such as carcasses during drought [44], and fox abundance has also been found to be higher in areas where dingoes are absent or controlled [30, 34, 43, 46]. Dingoes could potentially suppress fox, and cat populations through intraguild predation, interference, and/or exploitative competition. Interference competition may include direct attack, exclusion from resource points, causing a change in habitat use or activity times, or by increasing stress levels through frequent avoidance behaviour.

Dingoes are currently excluded or controlled over most of the Australian pastoral zone for the protection of commercial stock. Understanding any role that dingoes play in controlling introduced predators could assist in seeking a balance between the control of dingoes for pastoral production and the protection of dingoes for broader biodiversity benefits.

This study aimed to test the hypothesis that dingoes can suppress feral cats and foxes by examining their interactions within a landscape scale enclosure. A pair of dingoes was reintroduced to a 37 square $\mathrm{km}$ fenced paddock in northern South Australia. Feral cats and foxes were reintroduced 4 months later, and all animals were monitored for up to 12 months using GPS datalogger collars. Interactions between species, mortality rates, and postmortems were used to determine if suppression was due to interference or exploitative competition and/or intraguild predation. Cats, and foxes were also introduced to an adjacent unfenced control area where dingoes were removed. Indices of cat, fox, and rabbit spoor were compared between the two areas. Two factors were critical to the study: firstly, that densities of dingoes, cats, foxes, and prey species were typical of those found in the wider environment, and secondly that all study animals were local inhabitants and familiar with the habitats present in the study area.

\section{Study Area}

A $37 \mathrm{~km}^{2}$ "Dingo Paddock" was fenced between July and November $2008\left(30.27^{\circ} \mathrm{S}, 136.93^{\circ} \mathrm{E}\right)$ on Stuart Creek Pastoral Station. The paddock is situated approximately $35 \mathrm{~km}$ north of Roxby Downs in northern South Australia and is enclosed on three sides by a $1.6 \mathrm{~m}$ high netting fence ( $50 \mathrm{~mm}$ holes) with a $50 \mathrm{~cm}$ floppy top curving inwards to keep dingoes, cats, and foxes within the paddock but allowing cats and foxes to climb in. The netting fence was based on the Arid Recovery fence design [47] but was built from $50 \mathrm{~mm}$ netting to allow small rabbits to pass through the fence. The southern boundary of the paddock is shared with the Arid Recovery Reserve's Red Lake exclosure and is a $1.15 \mathrm{~m}$ high netting fence made from $30 \mathrm{~mm}$ netting with a floppy top overhang facing the dingo paddock. This study was conducted between December 2008 and December 2009 and formed part of a larger predator behaviour study which began in January 2008.

The southern section of the Dingo Paddock comprised a clay interdunal swale more than $2 \mathrm{~km}$ wide and vegetated with chenopod shrubs, bladder saltbush (Atriplex vesicaria), Oodnadatta saltbush (A. omissa), and low bluebush (Maireana astrotricha). Longitudinal orange sand dunes supporting sandhill wattle (Acacia ligulata) and sticky Hopbush (Dodonaea viscosa) shrublands were present in the northern sections, separated by 100 to $400 \mathrm{~m}$ wide swales. Other habitats include mulga (Acacia aneura) sandplains, patches of dune canegrass (Zygochloa paradoxa), and a breakaway range comprising silcrete capped hills with colourful eroding shale slopes in the western section of the paddock. Three ephemeral creeklines dissected the paddock from south to north and were characterised by denser vegetation cover and shallow sandy beds usually 1-2 m in width. Creeks flowed after rain into a near-permanent dam, a bulldozed depression in the soil located in the northern section of the paddock. The dam contained water throughout the study, and water was also present at three minor pipeline leaks along the southern boundary.

We chose an unfenced control area south of the dingo fence, a man-made wire netting fence erected to exclude dingoes from southern sheep grazing areas. The control area was on adjoining Mulgaria Pastoral Station and situated $5 \mathrm{~km}$ east of the Dingo Paddock, a distance considered sufficient to ensure independence but close enough to contain similar habitat types and reflect similar climatic events. Habitats within the control area were similar to the Dingo Paddock with a large clay swale, an area of closely spaced sand dunes, a pastoral dam, and an area of breakaways. The dam within the control area was stocked with domestic cattle (Bos taurus). 


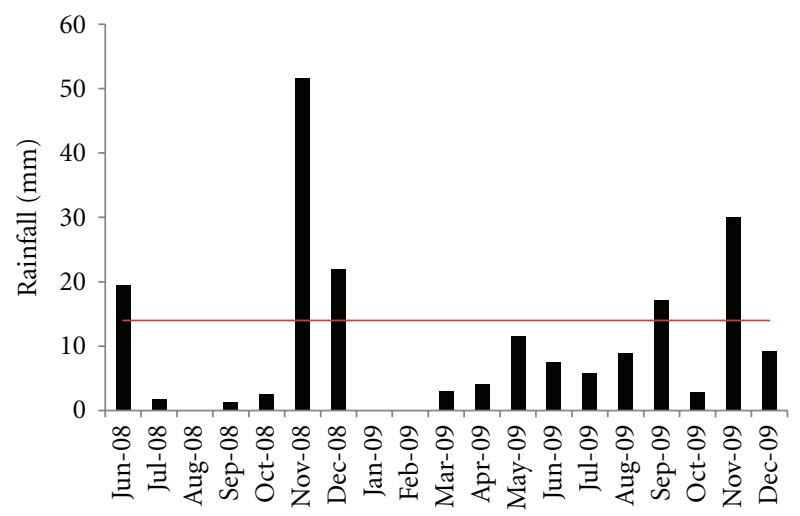

FIGURE 1: Rainfall recorded 6 months prior and during the study period. The line indicates the monthly average.

The Roxby Downs' climate is arid, failing to reach its long-term average rainfall of $166 \mathrm{~mm}$ in $60 \%$ of years [48]. Rainfall is aseasonal and with equal likelihood of rain during any month. Productivity within arid zone ecosystems is driven by unpredictable rainfall events, and only $100 \mathrm{~mm}$ of rainfall was recorded in both 2008 and 2009, leading to prolonged dry conditions. A significant rainfall event occurred just prior to the study in November 2008 (Figure 1), which filled the dam within the paddock and led to a flush of grass growth. However, conditions then remained relatively dry until the end of the study period.

\section{Methods}

3.1. Dingoes. In December 2008, a male and female dingo were captured from Stuart Creek Pastoral Station and released into the paddock. The wild dingoes were captured using soft catch Jake foot hold traps set around a cattle carcass located approximately $50 \mathrm{~km}$ north of the dingo paddock. Traps were fitted with springs to reduce injury and were checked in the late evening and again at dawn. No teeth damage was recorded after capture. We lightly anaesthetised the captured adult dingoes using a mixture of $1 \mathrm{~mL}$ of Medetomidine Hydrochloride and $0.5 \mathrm{~mL}$ of Ketamine, administered intramuscularly.

The anaesthetic was reversed using $0.5 \mathrm{~mL}$ of Atipamezole Hydrochloride. Anaesthetic and reversal doses for all animals were prepared in advance by a qualified veterinarian who also trained all animal handlers in correct administration of the preprepared doses. An anaesthesia procedure was developed and approved by the Wildlife Ethics Committee, including monitoring of rectal temperature during anaesthesia. Dingoes were weighed, checked for reproductive condition, and fitted with Global Positioning System (GPS) datalogger ARGOS satellite collars with VHF (SIRTRACK, Havelock, New Zealand) that nominally recorded fixes every 2 hours. Collars weighed $640 \mathrm{~g}$ and were no more than $4 \%$ of dingo body weight, less than the manufacturer's, and South Australian Wildlife Ethics Committee's maximum approved proportional collar weight of 5\%. Dingoes were transported in an air-conditioned car and released at the dam within the dingo paddock on the same morning as capture. Dingoes were checked after two hours and were then radiotracked daily for the first week. Radiotracking fixes indicated that both dingoes began moving throughout the paddock within a few hours of release. Although the number of dingoes placed in the paddock mirrored regional density, we provided a food subsidy to determine whether the availability of prey was limited in the paddock and could have influenced study outcomes. Between December 2008 and October 2009, kangaroo or rabbit carcasses and occasionally meat offcuts were placed at least fortnightly at a carcass dump established near the dam within the dingo paddock. Two remote motion sensor cameras (DVR Eye, Pix Controller, PA, USA) were placed at the carcass dump to record activity.

Weekly ARGOS satellite downloads were used to check whether the dingoes were in the paddock, and we conducted daily fence checks during the first month to repair any attempts to dig out under the fence. We recaptured the male and female dingoes in January and March 2010, respectively, to replace the GPS collars before the VHF batteries expired. No collar-related injuries such as rubbing or ulcerations were recorded. The male was captured using a single soft catch Jake trap set under an Acacia ligulata bush using a cat's head as bait, and the female was captured along the fenceline using a single Victor Soft-Catch (No. 1.5) trap. During the study, the pair of dingoes successfully raised a single male dingo pup born in June 2009. The female started using the breeding den in the northern sand dunes of the paddock on June 1 and continued to use it until July 16. After this time, the female and pup moved around the paddock and frequently changed shelter sites.

3.2. Cats and Foxes. Feral cats that remained in the paddock after construction were trapped in August 2008 and fitted with GPS data logger radiocollars with VHF (SIRTRACK, Havelock North, New Zealand) for a separate study comparing cat behaviour before and after dingo reintroduction. Cats were fitted with a small hind foot ring made from a cable tie with a $10 \mathrm{~cm}$ length of light chain attached. The chain dragged behind the cat when it moved and left a small indentation in soft substrate where tracks could be detected indicating that the cat had been fitted with a radiocollar. All cat tracks recorded during quad bike traverses of the 
paddock immediately after trapping were from collared cats suggesting that most, if not all, cats within the paddock had been captured and radiocollared. Only two of these cats still remained alive when additional cats and foxes were placed in the paddock in April 2009 and by then foot rings had been removed.

Between April and October 2009, 4 to 10 months after the dingoes were released into the paddock, we captured six feral cats and seven foxes, fitted them with radiocollars, and released them inside the dingo paddock. The majority of these cats and foxes were captured outside the paddock within $10 \mathrm{~km}$ of the dingo paddock in similar habitat (Table 1). However, one feral cat and one fox were captured inside the paddock, after the remote cameras detected that new animals had breached the fence and were visiting the carcass dump. The two radiocollared cats from a previous experiment that were resident in the paddock when the study began in April 2009 were also monitored during the study. Four of the seven foxes and all cats were captured in areas where dingo tracks are regularly observed suggesting they were not naive to dingo presence. Animals were captured using Victor Soft-Catch (no. 1.5) rubber jawed leg-hold traps fitted with springs to prevent injury (Coast to Coast Vermin Traps). Two lures were used in association with the traps; "pongo" (cat urine) and occasionally a Felid Attracting Phonic "FAP" (Westcare Electronics). Traps were checked in the evening or early each morning and captured feral cats and foxes were restrained using gloves and towels and anaesthetised with a mixture of medetomidine hydrochloride and ketamine administered intramuscularly. It was not possible to weigh animals before sedation so doses were preprepared for small (less than $5 \mathrm{~kg}-0.32 \mathrm{~mL}$ of medetomidine and $0.2 \mathrm{~mL}$ of ketamine) and large (more than $5 \mathrm{~kg}-0.4 \mathrm{~mL}$ medetomidine and $0.25 \mathrm{~mL}$ of ketamine) cats and adult foxes ( $1 \mathrm{~mL}$ of medetomidine and $0.5 \mathrm{~mL}$ of ketamine).

We weighed and sexed the cats and foxes and noted the condition of their teeth, body, and reproductive organs. Only animals weighing at least $2.7 \mathrm{~kg}$ were used in the study to ensure radiocollars remained less than $5 \%$ of body weight (Table 1). The $135 \mathrm{~g}$ GPS data logger collars with VHF transmitter (SIRTRACK, Havelock North, New Zealand) were constructed from synthetic belting, and recorded GPS fixes every 2 hours. The units were housed in epoxy resin and contained 2 antennas, micromouse GPS and $220 \mathrm{~mm}$, 2NC gauge whip antenna. The VHF transmitter (40/80 ppm) was equipped with a mortality sensor, triggered after longer than 24 hours without movement. The rectal temperature was taken every 3 minutes whilst under anaesthetic and cold packs were placed between the hind legs if the body temperature rose above 39 degrees Celsius. Animals were then administered the reversal drug atipamezole hydrochloride, placed in a cage trap covered by a towel in a vehicle and only released when they had fully recovered. If the ambient temperature was over 30 degrees Celsius, the towel was moistened and the vehicle air conditioned. We released animals at the dam or within sand dunes in the dingo paddock and watched to ensure they ran off after the cage trap was opened. They were radiotracked either later that day or early the following day to ensure they had moved.
Between September and December 2009, we captured and radiocollared an additional three foxes and three feral cats and released them into the unfenced Mulgaria control area to act as controls. One control cat was trapped in the Mulgaria control area, and the other two control cats were captured within $15 \mathrm{~km}$ of the control area. All control foxes were captured on Roxby Downs Station, $50 \mathrm{~km}$ south of the dingo paddock, two in October 2009, and one in December 2009.

Between April and December 2009, we radiotracked all collared animals within the dingo paddock and control area weekly or fortnightly on foot, quadbike, or from a Cessna 172 aeroplane with a wing-mounted aerial. If an animal was found dead, its location was recorded and a thorough search of the death location ensued. Habitat, tracks, scats, bones, fur, warrens, or any other signs of interest were recorded. Any fresh carcasses were sent to Zoos South Australia where postmortems were performed by qualified veterinarians.

3.3. Data Analysis. We converted collar downloads from Greenwich Mean Time to Australian Central Standard Time (nondaylight saving) and plotted them using Arc GIS software. Collar accuracy varied according to the number of satellites available at the time of the GPS fix, but precision was usually less than $10 \mathrm{~m}$. For deceased animals, GPS fix locations were used to confirm the point of death by identifying clusters of points in the same location indicating no movement for an extended period. The time of death was estimated as the time interval between the first GPS fix at the death location and the time of the last GPS fix recorded in an area prior to the death location, which typically permitted time of death to be estimated to be within 2 hrs. In cases where multiple clusters of fixes were evident at a number of localities within a $1.5 \mathrm{~km}$ radius, ground searches revealed that carcasses had been dragged after death, and the first cluster was identified as the kill site. Time and location of death of all cats and foxes within the paddock were compared to dingo GPS fix locations for the same period to determine whether the dingoes were present at the death location within the correct time interval. Other factors were also considered when determining the cause of death, including the results of any autopsy and presence of dingo tracks.

The distances between all fox and dingo GPS fix locations at each $2 \mathrm{hr}$ interval was used to determine if any possible encounters had occurred between the two species prior to death. Given that the approximate dimensions of the paddock were $7 \mathrm{~km}$ by $5 \mathrm{~km}$, distances of less than $500 \mathrm{~m}$ between animals within a $4 \mathrm{hr}$ time interval were conservatively considered possible encounters. Additionally, all GPS fix locations within $24 \mathrm{hrs}$ of death were closely compared to dingo locations to determine if the dingoes had followed the foxes prior to death. GPS fix locations of cats and dingoes were also compared but only for the $24 \mathrm{hr}$ period prior to death as cats remained alive longer than foxes and produced significantly more GPS fix locations for analysis.

To investigate the influence of fox presence on dingo activity, each dingo's minimum daily distance moved was compared on days when foxes were present and absent in 


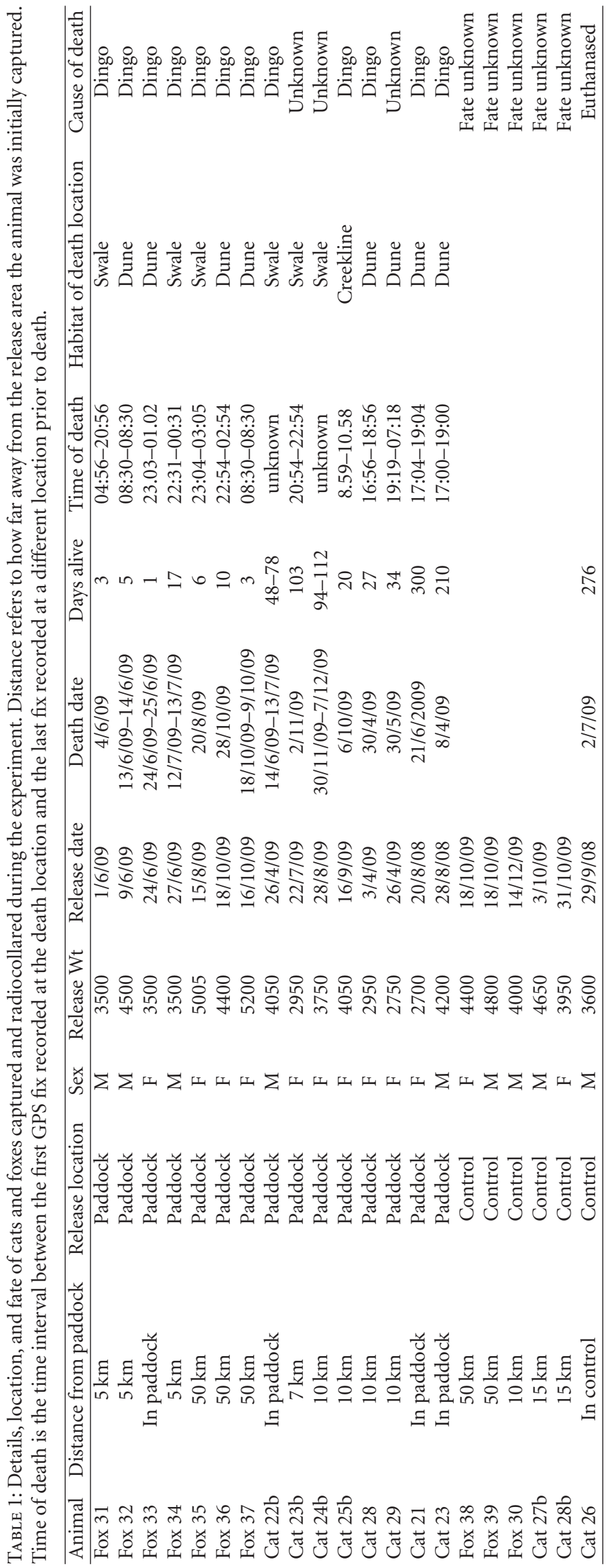




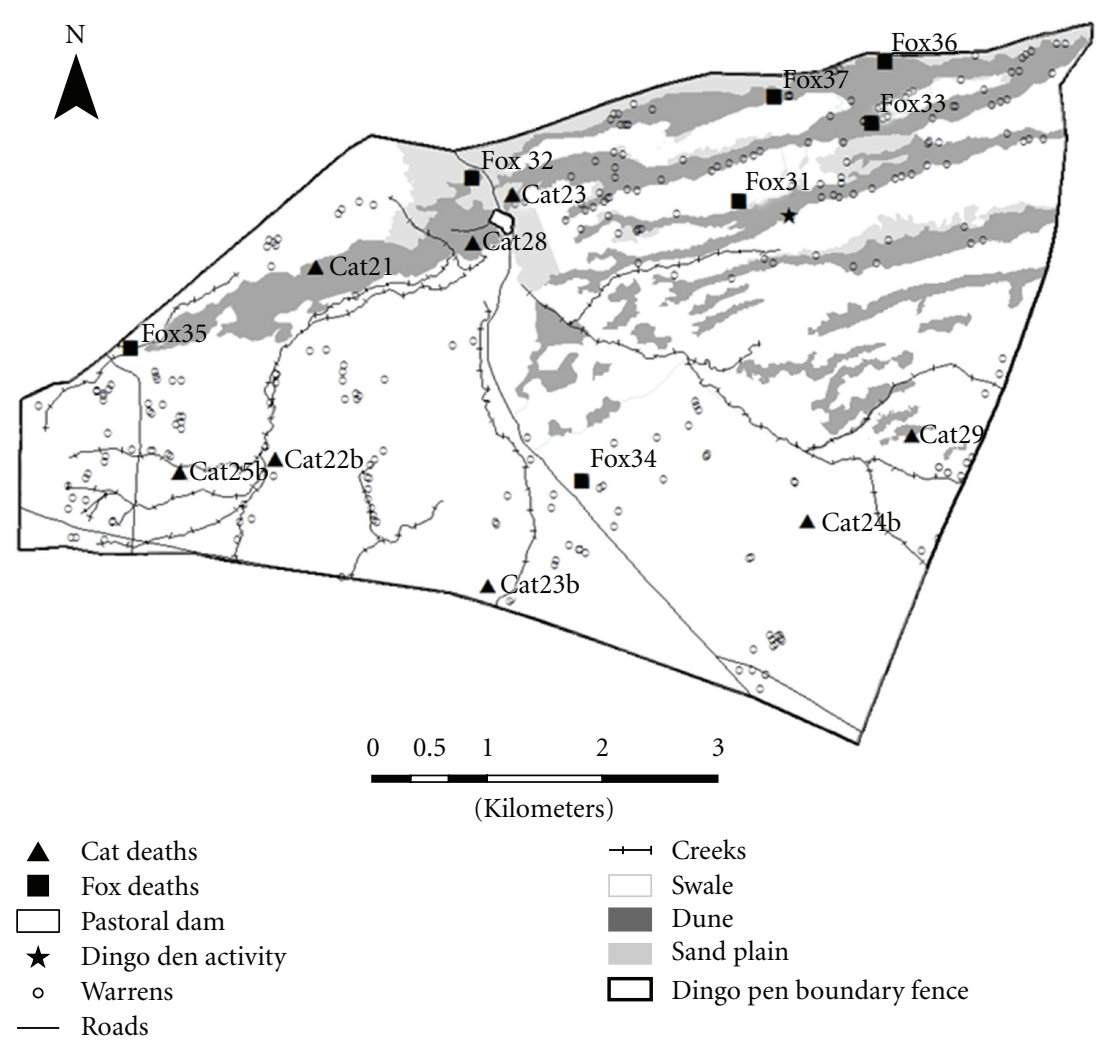

Figure 2: Location of animal deaths attributed to dingoes within the Dingo Pen. Habitat types, rabbit warrens, and the dingo den site are also marked.

the paddock. Minimum daily distance was calculated as the total distance between successive GPS fix locations over a $24 \mathrm{hr}$ period. At least one fox was in the paddock over three different periods between June and October for 34, 6, and 13 consecutive days, respectively. Minimum daily distances during these times were compared with the remaining 161 days when foxes were absent during the study period. Male and female dingoes were analysed separately using one-way ANOVAs.

3.4. Prey Abundance. Red kangaroos (Macropus rufus) remained present in both the dingo paddock and control area throughout the study. European rabbit (Oryctolagus cuniculus) warrens were common throughout the sandy dunes, and sandplains and clusters of larger, more permanent rabbit warrens were located in calcrete outcrops throughout the clay swales. Warren systems of the spinifex hopping mouse (Notomys alexis) were present throughout the sand dunes and, along with the Bolam's mouse (Pseudomys bolami), have consistently been the most common small mammal present on regional sand dunes over the preceding decade [49]. Other small mammals including the introduced house mouse (Mus musculus) and dunnarts, Sminthopsis spp. also occur in the region but at low densities and are usually restricted to the clay interdunal swales [49].

Indices of dingo, fox, cat, and rabbit activity were derived from the presence of spoor along $200 \mathrm{~m}$ track transects established in both the control and dingo paddock in the three main habitat types: sanddune, swale, and creekline. Swale transects were all placed on roads where suitable substrate for tracking existed. Transects were swept clean using a metal bar dragged behind a quadbike the night before the first of two consecutive mornings of track counts. Data from the two mornings were combined to give a presence/absence score for each transect for each monitoring period. A total of 39 transects (20 sand dune, 10 creeklines, and 9 swale) were established in the dingo paddock and 38 (20 dune, 8 creekline, and 10 swale) in the control area. All transects were sampled every 4 months from February 2008 until February 2010. Sampling began 11 months prior to dingo reintroduction and continued for 3 months after the completion of the experiment.

\section{Results}

4.1. Foxes. All seven foxes released into the dingo paddock died within 17 days of release (Table 1). GPS fix locations, kill site inspections, and autopsies suggested that all seven animals were killed by dingoes. One fox appeared to have been killed by the female on her own when the male was at the den site. All other deaths occurred when the dingoes were travelling together. Where the time of death was known, foxes died between $10.30 \mathrm{pm}$ and $3 \mathrm{am}$ (Table 1). Four of the animals died on sand dunes and three on swales (Figure 2). None of the deaths occurred in areas of dense vegetation. Deaths were recorded at various locations around the paddock with no apparent association with the breeding 
den or resource points (Figure 2). Additionally, the deaths were recorded both during and after the female whelped. There was no indication that any of the foxes had been eaten and most exhibited little external sign of injury. Some carcasses were mauled and parts dragged up to $1500 \mathrm{~m}$ after death. In the four cases where the fox carcass was not retrieved for more than $12 \mathrm{hrs}$ after death, the dingoes either remained with or returned to the carcass for up to 6 days after death (Table 2).

Three of the seven foxes (Fox 32, 36, and 37) were found within a few hours of death and could be necropsied (Table 2). Injuries sustained included ruptured leg muscles and/or trauma to the lumbar region and ribs with herniation of the abdominal muscles resulting in extensive and terminal haemorrhaging. Veterinarians from Zoos South Australia indicated that the injuries were consistent with an attack by dingo or dingoes. In one instance, the fox had been chased several times at high speed around a bush. In another, scrape marks and diggings suggested that the fox had been flushed out of a warren on a sand dune.

Tracks and GPS fix locations from the dingoes and foxes suggested that they also killed three other foxes (Table 2), with one or both dingoes recorded less than $10 \mathrm{~m}$ from the death points during the time of death. The remaining fox, Fox 31, was within $110 \mathrm{~m}$ of the male dingo when it died. After death, the fox and male dingo GPS fix locations were within $10 \mathrm{~m}$ of each other at two different cluster locations up to $1.5 \mathrm{~km}$ from the kill site suggesting that the carcass was dragged after death. Unfortunately the collar failed to record most of the female dingo fixes taken during the $17 \mathrm{~h}$ death period, but she was travelling with the male just prior to the death period.

There were no recorded interactions between the foxes and dingoes prior to fox deaths. The only instance when dingo and fox fixes were recorded within $500 \mathrm{~m}$ of each other within a $4 \mathrm{~h}$ time interval was at the time of fox deaths. Furthermore, outside this $4 \mathrm{hr}$ window, more than $450 \mathrm{~m}$ and $12 \mathrm{~h}$ were recorded between any fox and dingo locations suggesting that the first physical encounter between dingo and fox was also the last. There was also no indication that dingoes were following foxes prior to death as both species were moving in different directions, and the distance between fox and dingo GPS fix locations recorded just prior to death was between 1703 and $3000 \mathrm{~m}$ (Table 2). No fox deaths were recorded along fencelines or roads despite both foxes and dingoes regularly using these features during the study. One fox collar did not store any fixes during its time in the dingo paddock so predeath interactions with the dingoes could not be determined.

There was a strong trend towards longer daily movements in male and female dingoes when foxes were present in the paddock compared with when foxes were absent (female $F=3.847, d f=1,213, P=0.051$; male $F=3.434$, $d f=1,213, P=0.065)$ but results were not significant. The average minimum daily distance moved by the female dingo increased from $2782 \mathrm{~m}$ to $3617 \mathrm{~m}$ when foxes were present in the paddock and the male average increased from $3375 \mathrm{~m}$ to $4267 \mathrm{~m}$.
4.2. Cats. All six feral cats released into the paddock died between 20 and 123 days after being translocated into the paddock, and we recorded evidence that at least three cats were killed by dingoes. An additional two cats already present and radiocollared in the paddock when the experiment began also appeared to have been killed by dingoes. Where dingoes were implicated in deaths, three occurred in the early evening and one in the mid morning. When the female dingo killed two cats on her own, the male dingo was at the den site, more than $1 \mathrm{~km}$ from the death points. Deaths occurred before, during, and after denning and were in different habitat types and locations around the paddock (Figure 2). Dingoes displayed similar postdeath behaviour to that shown with killed foxes, staying with and/or returning to carcasses after death.

A postmortem confirmed death by dingo attack in one cat (cat 28, Table 2), but the 4 remaining cats were too decomposed for autopsy, so tracks, dingo behaviour, and GPS fix locations were used to determine if the dingoes may have been involved in the cat deaths. Although in two instances (cat 25b and cat 23) the dingo fixes were several hundred metres from the cats during the death period, other factors such as direction of predeath movement, postdeath dingo behaviour, and tracks and saliva marks suggested that the cause of death was dingo attack.

The cause of death could not be determined for three of the cats (Table 1). Cat 23b was several kilometres from the dingoes when it died out on a swale. Its remains were found under a wedge-tailed eagle (Aquila audax) nest suggesting that it may have been killed or scavenged by an eagle. The other two cats were within $350 \mathrm{~m}$ and $400 \mathrm{~m}$ of the dingoes during the death period, and it is possible that the dingoes were involved in these deaths. Of the five cats that remained in the paddock long enough to be recaptured and recollared during the study, two had lost weight, one had maintained weight and one had gained weight.

Collars were removed from dead cats and foxes, and no rubbing or collar-induced injuries were detected. The dingoes were recaptured 12-18 months after initial capture, and no collar injuries were detected.

4.3. Control Animals. Only one cat and no foxes could be relocated after release into the control area. The cat that was captured within the Mulgaria control area remained in the control area for 276 days before it was recaptured and euthanased at the end of the experiment. This cat sheltered extensively in rabbit warrens on rocky swales, and, although usually staying within a $12 \mathrm{~km}$ linear area, it was known to travel more than $35 \mathrm{~km}$ to the south and back again within a two week-period. This cat was recaptured three times over the study and, its weight remained between 3350 and $3600 \mathrm{~g}$.

All other control animals were transferred to the control area from surrounding areas, and, despite more than five attempts to locate them using a light aircraft, they could not be found. Searches from the air included a $20 \mathrm{~km}$ radius around the control site, all of the original capture locations and $1 \mathrm{~km}$ traverses across the control area. The fate of these 


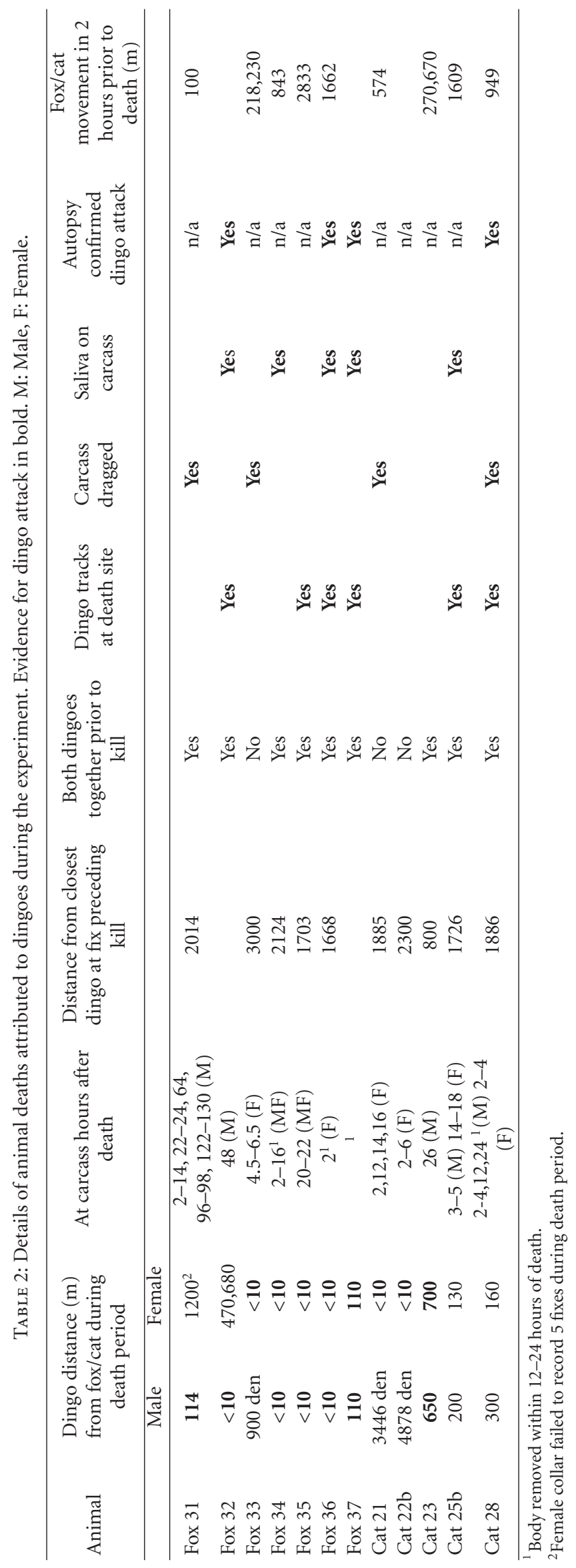




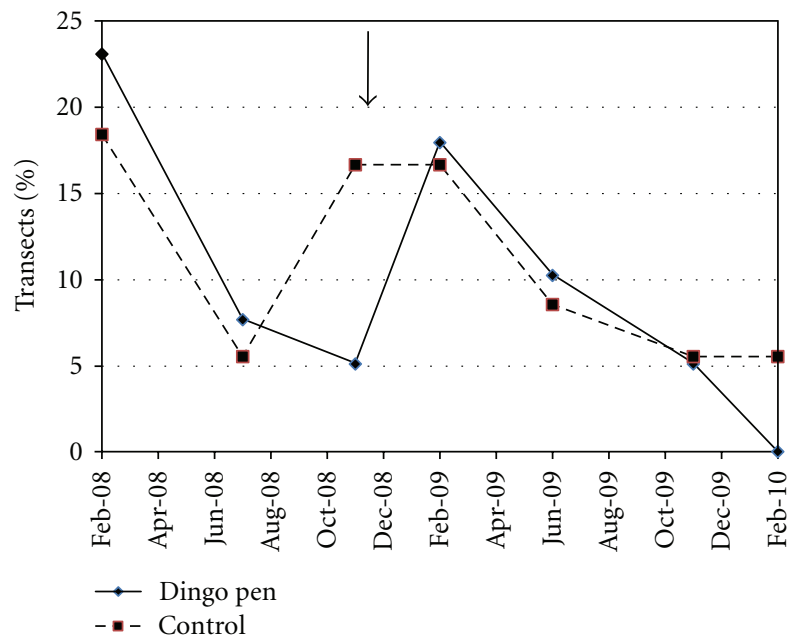

Figure 3: The percentage of transects (Dingo Pen $n=39$, control $n=38$ ) with cat tracks recorded at sites within the Dingo Pen and control area. Cats were added to the Dingo Pen between April and October 2009 and to the control area in October 2009. The pen was completed in November 2008, and the arrow indicates when dingoes were released.

animals remains unknown, but it is likely that they moved away from the control area.

4.4. Track Transects. Prior to and during fence construction, tracks, sightings, and scats of wild dingoes, feral cats, and foxes were all observed within the dingo paddock area. However, spoor counts and spotlighting transects indicated that there were no foxes or dingoes present in the paddock when the fence was completed. Subsequent spoor counts and remote cameras detected two uncollared foxes and two uncollared cats that had climbed into the paddock at different times during the experiment.

Both control and dingo paddock transects exhibited similar trends of cat activity during the initial stages of the project (Figure 3). However, despite the presence of at least five cats in the paddock prior to dingoes being released in December 2008, as well as the addition of 4 cats in 2009 and another cat that was captured after climbing into the paddock, cat activity declined to zero by February 2010. All ten of these cats were radiocollared, and all died during the experiment. Cat activity fluctuated in the control area, but cats remained present throughout the experiment. Both areas experienced a decline in activity in 2009 , possibly partly due to the dry conditions experienced during this time.

Fox spoor was recorded in the paddock when foxes were released in June but declined to zero by the end of the experiment. Fox activity in the control area was variable over the study period (Figure 4). The presence of rabbit spoor on transects followed similar trends at both dingo and control sites and were recorded on 50 to $85 \%$ of track transects in the dingo and control areas during 2009 (Figure 5). Inside the dingo paddock, dingo tracks were present on an average of $27 \%$ of track transects during the study period. The control area averaged dingo tracks on $4 \%$ of transects suggesting very low dingo activity.

\section{Discussion}

Many previous studies have suggested that dingoes suppress fox abundance $[2,4,33-36,46]$, but this is the first time that a direct negative interaction between dingoes and cats and foxes has been demonstrated. Small amounts of cat hair have been recorded in dingo scats [42], and some researchers have suggested that study cats were killed by dingoes [40]. However, other researchers have suggested that the presence of dingoes may assist cat survival by providing carrion [50]. Similar studies in North America have reported 25\% of radiocollared cats killed by coyotes [23]. Both male and female, and large and small, animals were killed by dingoes in our study suggesting that all foxes and cats may be susceptible to dingo attack.

The primary mechanism for suppression of cats and foxes by dingoes in this study appeared to be direct physical attack rather than suppression of breeding or exclusion from resource points as has been suggested elsewhere [44]. The dingoes did not eat any of the carcasses, despite staying with and/or returning to them for extended periods, which suggests that they were killing due to interference competition rather than intraguild predation. Similar results were found by Molsher et al. [51] for red foxes and cats in Australia and Helldin et al. [52] for lynx (Lynx lynx) and red foxes in Sweden, and radiocollared animals were killed but rarely eaten by the dominant predator. However, intraguild predation has been previously recorded in dingoes. Marsack and Campbell [39] observed dingoes eating foxes in arid Western Australia, and both fox and cat remains have been found in dingo scats and stomach contents [39, 42-45]. Intraguild predation has also been recorded in the United States of America where cats are eaten by coyotes and can contribute up to $13.1 \%$ of coyote diet [53-55]. It is likely that mesopredator suppression mechanisms are influenced by resource availability, habitat type, breeding season, and 


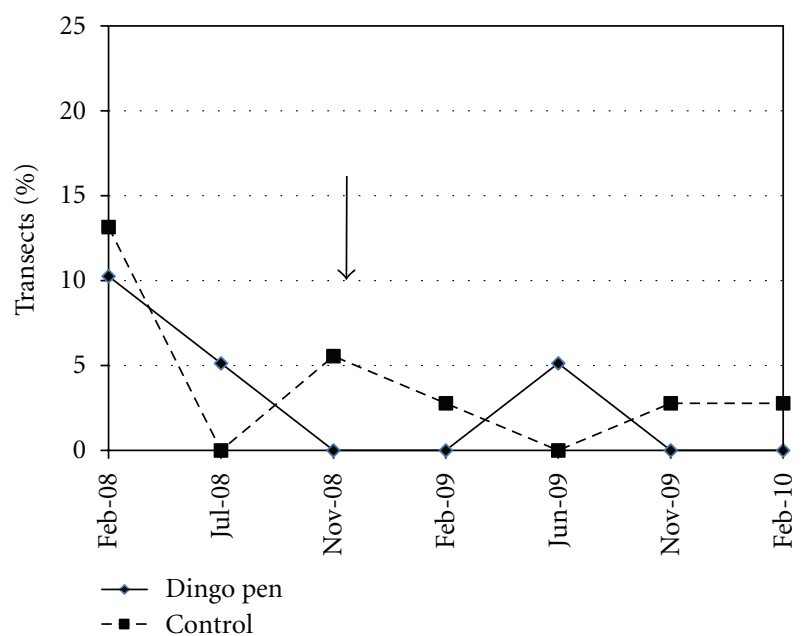

FIgure 4: The percentage of transects (Dingo Pen $n=29$, control $n=38$ ) with fox tracks recorded at sites within the Dingo Pen and control area. Foxes were released into the Dingo Pen between June and October 2009 and into the control area between October and December 2009. The pen was completed in November 2008 and the arrow indicates when dingoes were released.

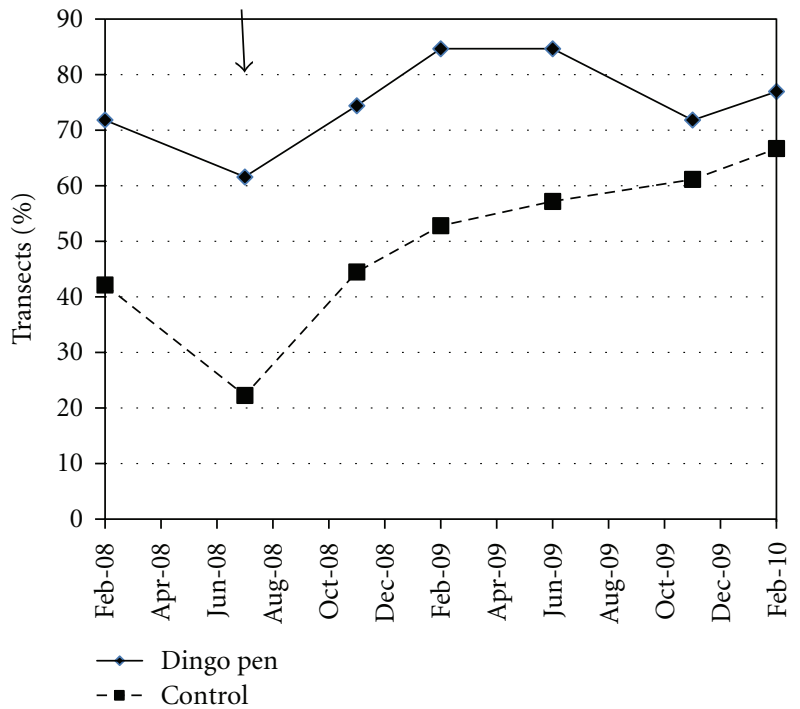

Figure 5: The percentage of transects (Dingo Pen $n=39$, control $n=38$ ) with rabbit tracks recorded within the Dingo Pen and control area. The arrow indicates when dingoes were released into the pen in December 2008.

intraspecific behavioural differences. Interestingly, most animals killed by dingoes showed very little external sign of injury suggesting that many "unexplained" deaths of radiocollared cats and foxes in other studies previously attributed to nutritional stress (e.g., [56]) may have been the result of dingo attack.

Although cats were subjected to direct dingo attack, other forms of suppression may also have been occurring in the paddock. Burrows et al. [15] found higher breeding success of cats in the area from which foxes and dingoes had been controlled. Despite lactating cats being captured within the paddock in our study, and kitten spoor being found briefly at 1 cat den site, no successful cat recruitment was recorded. Juvenile cat spoor was not recorded on any track transects nor were any young uncollared cats photographed at the carcass dump. Other studies have suggested that dingoes may change cat's spatial behaviour, and both Edwards et al. [56] and Palmer (pers. obs) found cats used wooded or mulga habitat more than open habitats when dingoes were present, possibly due to predation risk by dingoes. One cat in the paddock was found to frequently shelter in a wedge-tailed eagle nest in a mulga tree, one of the few trees in the paddock that was above $2 \mathrm{~m}$ in height. Cat deaths were recorded in all habitat types suggesting that habitat may not have influenced predation risk in our study, but this result may not be consistent in wooded habitats.

Fox and cat deaths occurred at times when they were most active, foxes at night time and cats mainly at dusk. This 
is consistent with dingoes killing cats and foxes when they encounter them rather than digging them out of warrens or using olfactory cues to seek them out. Corroborating this assumption was the independent movement patterns of dingoes, cats, and foxes in the $24 \mathrm{hrs}$ prior to death and deaths occurring when animals unknowingly moved into the path of the dingoes or vice versa. Therefore, it is likely that dingoes killed cats and foxes on an opportunistic basis, but they were probably aware of the foxes in the paddock and may have increased their daily movements to increase the chances of encountering them.

Containing all three animal species within a paddock, albeit a landscape scale one, may have influenced the outcomes of the study by restricting the movement of some cats and foxes and perhaps rendering them more likely to encounter or be cornered by a dingo. The home range of cats and foxes vary considerably in the arid zone with averages of between 20 and $30 \mathrm{~km}^{2}$ commonly recorded [15, 20,56]. The average cat and fox home range recorded in the study area during a previous study was $16-17 \mathrm{~km}^{2}$ with a range of 0.5 to $123 \mathrm{~km}^{2}$ [20]. However, several factors suggest that the paddock represented a realistic arid zone environment. Although cat home ranges can be large, they do overlap [49] and track counts in control, and paddock areas were similar at the start of the study, suggesting that the density of cats during the experiment was similar to that naturally recorded outside the paddock. Five cats were resident in the paddock when it was fenced, a similar or higher density to that maintained during the experiment. Only one fox was present in the paddock at a time, and the density of 0.027 foxes per $\mathrm{km}^{2}$ is much lower than that recorded in other arid zone studies (0.46-0.52 [57], 0.6 [58]). Rabbit track counts suggested that food resources were similar in control and paddock areas, and the presence of a carcass dump provided supplementary food if required. Additionally, all animals used in the experiment were captured inside the paddock or from within $50 \mathrm{~km}$ in similar habitat.

The dingoes also appeared to have behaved typically, breeding in April/May and whelping in June, as recorded elsewhere in arid Australia [44]. The dingoes were recorded howling and scent marking and stopped trying to escape from the paddock after one week, also an indication that they were behaving like a dingo pack and maintaining a territory. Although dingo home ranges in the arid zone have been reported to be up to $77 \mathrm{~km}^{2}$ [44] and even as large as $272 \mathrm{~km}^{2}$ [59], other studies have reported arid zone dingo density between 1 and 22 per $100 \mathrm{~km}^{2}$ (usually 5) [60], similar density to that recorded in the paddock during our study. Pack size of two dingoes is commonly recorded in the arid zone [60]. Dingoes are known to feed on rabbits, reptiles, kangaroos, and carrion [41], all of which were present during the study. Thus, although the paddock may have influenced the results, the large size, availability of different habitat types, densities of predators, and presence of suitable food and rabbit warrens for shelter should have minimised these influences.

Deaths were recorded at various times between April and October, before, during and, after the denning period. It is not known if dingoes will kill cats and foxes over the summer months. Although resident cats in the paddock when the dingoes were introduced in December were not killed until April or June, the dingo pair may have been more likely to influence other predators or competitors once they had formed a pack and started defending resources [61]. The female was only recorded killing animals on her own during her 6-week denning period when the male was guarding the den site. Dingoes may consider foxes and cats a threat to their pups and increase their intolerance of them during the breeding season. In North America, coyotes were also found to kill domestic cats at any time of year but with higher kill rates during puprearing [62].

Several animals appeared to have been chased around bushes or over short distances prior to death. The dingoes were travelling together when nine of the 12 foxes and cats were killed. It is impossible to determine if both dingoes assisted in the kills, but it appears likely, as dingoes regularly hunt and kill prey cooperatively [63]. Additionally, tracking observations of a fox killed by dingoes in a separate arid site in South Australia indicated that 2 dingoes chased and killed a fox, whose fresh carcass was located on a sand dune (J.L. Read pers obs). The female dingo killed a large $4 \mathrm{~kg}$ cat, and there was no indication that any particular size or sex of cat or fox was less susceptible to dingo attack by lone or pack dingoes. Cooperative dingo packs will more effectively hunt large mammals such as macropods, buffalo, feral horses, or cattle $[43,63,64]$, but solitary dingoes can effectively hunt rabbits, small mammals, and sheep to achieve their daily energy requirements [41, 43,44]. Grubbs and Krausman [62] documented coyotes killing domestic cats in the United States of America and found that single coyotes were just as effective at killing domestic cats as coyotes hunting in groups. However, dingoes may be more efficient hunters of cats as coyotes only killed cats in just over $50 \%$ of interactions [62].

Of those cats killed by dingoes, the resident cats survived longer than the cats placed in the paddock, possibly suggesting that the resident cats were more familiar with shelter sites and able to avoid interactions with the dingoes for longer. However, three of the five cats placed in the paddock do not appear to have been killed by dingoes, and their causes of death are unknown. Feral cats in the arid zone are thought to suffer from periods of nutritional stress leading to high natural mortality of more than $50 \%$ in less than 12 months $[20,56]$. It appears unlikely that most cats were significantly nutritionally stressed as rabbit activity did not fluctuate significantly during the study period, and carcasses were regularly dumped at the carcass dump but rarely used by cats. Additionally, most recaptured cats either maintained or increased in weight. All of the cats and foxes placed in the paddock were adults and had been previously surviving unaided in the paddock or surrounding similar habitat. The death of two of these resident cats also suggests that it is unlikely that the translocation itself was responsible for other cat deaths. Two of these cats may have been preyed on by wedge-tailed eagles, but the third cat found down a rabbit warren may have died from natural causes.

Results from this study need to be extrapolated cautiously. Our experiment is a single replicate. Due to logistical constraints, we could only trial one pair of dingoes in a 
single paddock. Ideally, the experiment should be repeated using another dingo pair, and foxes and cats added in different seasons. It is likely that interactions between cats, foxes, and dingoes will vary depending on habitat types, breeding seasons, and food availability. The relatively open habitat in the paddock, despite numerous rabbit warrens for shelter, may have made it easier for dingoes to locate and catch cats and foxes. More wooded environments or areas with denser understorey may enable cats, foxes, and dingoes to coexist more readily. Despite similar habitat types in capture and release locations, for some animals, the paddock was an unfamiliar environment and may have influenced their susceptibility to dingo attack. Track searches of the paddock in early June 2010, 6 months after the experiment finished, located very low abundance of fox and cat tracks suggesting that these species had reinvaded the paddock. It is not known if dingoes permanently suppress cats and foxes over long periods or are more tolerant of cats and foxes outside the breeding period. Finally, drought conditions may have influenced results and increased dingo attacks due to competition for food resources.

Several studies have identified a loss in species biodiversity when a keystone or "apex" mammalian predator is removed [23, 28, 65]. The release of competitive restraints previously imposed on mesopredators can lead to changes in prey species' composition and diversity. Previous research has suggested that dingoes may suppress cat and fox abundance, but our trial is the first time that this has been proven experimentally. We found interference competition via direct attack to be the key suppression mechanism. However, the important question for threatened species conservation is whether the positive role that dingoes appear to play in suppressing cats and foxes will counteract dingo predation on these same threatened species and equate to a net benefit for native wildlife. We believe that there are several critical factors that will determine whether a native species may benefit from cat and fox suppression. Firstly, the size and behaviour of prey species may be important. Medium-sized native mammals that are preyed on by cats and foxes and dingoes may not benefit to the extent of smaller mammals, for which dingoes are less efficient predators. Although dingoes are known to prey on smaller mammals such as rodents [37, 41, 44], they are not preferred stable prey items and may only be targeted during natural irruptions when they are plentiful. Solitary, wide-ranging species such as the Greater Bilby (Macrotis lagotis) may benefit more than communal sedentary species such as the Burrowing Bettong (Bettongia lesueur). Sedentary, communal species are more conspicuous and easier to target by predators. Proposed continued monitoring of rabbit and small native rodent abundance inside and outside the Arid Recovery dingo paddock should elucidate the net ecological role of dingoes for these different-sized mammals. Furthermore, reintroducing threatened native mammal species with different social and movement systems into the dingo paddock will help determine whether positive suppression of cats and foxes outweighs any direct predation by dingoes.

Secondly, like other canids, foxes and dingoes both have a predisposition to kill several prey and consume only few or none of the total kill [66]. This behaviour, known as surplus killing, is why dingoes and foxes can pose a significant threat to native fauna and sheep populations; especially spatially restricted or threatened populations $[67,68]$. There is some evidence to suggest that surplus killing in the dingo is not as common or devastating to native wildlife as the introduced red fox [66], but this is yet to be proven experimentally.

Thirdly, the relationship between dingo density and the magnitude of cat and fox suppression will have a major influence on whether a net benefit to prey species is realised. If low dingo density, particularly in concert with established breeding territories [61], is sufficient to significantly suppress cat and fox abundance then the net predation impact is likely to be low, leading to a net benefit to some wildlife species. However, the abundance of dingoes has increased significantly since European settlement due to the proliferation of stock watering points and plentiful rabbits. If the density of dingoes required to adequately suppress cats and foxes for the protection of wildlife is significantly higher than pre-European densities, then any benefit to wildlife may be offset by artificially high predation rates by dingoes.

Finally, unlike cats and foxes, dingoes are dependent upon water, at least during summer. Therefore, in desert areas dingo density and their predation and mesopredator suppression will be spatially and temporally patchy compared with cats and foxes. Many desert animals rely on restricted refugia areas for survival during drought [69], and unless these refugia areas coincide with areas of mesopredator suppression, long-term benefits to wildlife may not occur.

\section{Management Implications}

Although the ecological role of the dingo requires further verification in other environments, our study supports a growing body of evidence that the dingo plays an important role in ecosystem function. Therefore, we recommend that functional dingo populations in rangeland areas are maintained at landscape scales and that dingo control for calf protection is restricted to targeted control during exceptional circumstances. Research should now focus on whether dingoes provide a net benefit to threatened wildlife species by investigating the influence of prey size and behavioural traits, surplus killing, and dingo density. We predict that smaller, solitary, and wide-ranging native species close to permanent watering points will benefit the most from mesopredator suppression. Finally, the red fox, feral cat, and dingo all have catholic diets that can change rapidly depending on resource availability. Despite the dingo arriving in Australia several thousand years ago, all three species are relatively new arrivals in Australia. Researchers should consider that the mechanisms and benefits of mesopredator suppression in Australia may not mirror those recorded in North America and Europe where mesopredators are usually native and their diets more prey specific.

\section{Acknowledgments}

This study was conducted by Arid Recovery, a joint conservation initiative between BHP Billiton, the S.A. Department 
for Environment and Natural Resources, The University of Adelaide and the local community. Funding was provided by the South Australian Arid Lands Natural Resource Management Board, Olympic Dam Expansion Project, and Arid Recovery. Greg Kammermann and his assistants worked tirelessly on building the dingo paddock on time and within budget. Many other volunteers and staff have contributed to this work, particularly, A. Kilpatrick, A. Clarke, T. Moyle, D. Sandow, C. McGoldrick, G. Miller, and B. Arnold. Thanks are due to M. Lloyd for providing carcasses for our carcass dump and assisting with fox captures. Rob Savage gave permission to use Mulgaria Station as a control site, and Dr D. Paton provided useful comments on the manuscript. The authors are indebted to the veterinarians from Zoos South Australia, in particular I. Smith, W. Boardman, and D. McLelland, who conducted the necropsies, provided veterinary advice, and assisted with attempting to retrieve the dingo collars. Dr A. Melville-Smith from the Roxby Downs Veterinary Clinic assisted with anaesthesia dosages and training. This study was conducted under ethics approval (permit no. 6/2007M3) from the South Australian Wildlife Ethics Committee.

\section{References}

[1] J. H. Seebeck, "Status of the barred bandicoot Perameles gunnii, in Victoria with a note on husbandry of a captive colony," Australian Wildlife Research, vol. 6, pp. 255-264, 1979.

[2] A. P. Smith and D. G. Quin, "Patterns and causes of extinction and decline in Australian conilurine rodents," Biological Conservation, vol. 77, no. 2-3, pp. 243-267, 1996.

[3] J. Short, "The extinction of rat-kangaroos (Marsupialia:Potoroidae) in New South Wales, Australia," Biological Conservation, vol. 86, no. 3, pp. 365-377, 1998.

[4] C. N. Johnson, J. L. Isaac, and D. O. Fisher, "Rarity of a top predator triggers continent-wide collapse of mammal prey: dingoes and marsupials in Australia," Proceedings of the Royal Society B, vol. 274, no. 1608, pp. 341-346, 2007.

[5] J. Short, S. D. Bradshaw, R. I. T. Prince, and G. R. Wilson, "Reintroduction of macropods (Marsupialia: Macropodoidea) in Australia-A review," Biological Conservation, vol. 62, no. 3, pp. 189-204, 1992.

[6] P. E. S. Christensen and N. D. Burrows, "Project desert dreaming: the reintroduction of mammals to the Gibson Desert," in Reintroduction Biology of Australian and New Zealand Fauna, M. Serena, Ed., pp. 199-208, Surrey Beatty and Sons, Chipping Norton, New Zealand, 1995.

[7] D. F. Gibson, G. Lundie-Jenkins, D. G. Langford, J. R. Cole, D. E. Clarke, and K. A. Johnson, "Predation by feral cats, Felis catus, on the rufous hare-wallaby, Lagorchestes hirsutus, in the Tanami Desert," Australian Mammalogy, vol. 17, pp. 103-107, 1994.

[8] R. Southgate and H. Possingham, "Modelling the reintroduction of the greater bilby Microtus lagotis using the metapopulation model analysis of the likelihood of extinction (ALEX)," Biological Conservation, vol. 73, no. 2, pp. 151-160, 1995.

[9] D. Priddel and R. Wheeler, "An experimental translocation of brush-tailed bettongs (Bettongia penicillata) to western New South Wales," Wildlife Research, vol. 31, no. 4, pp. 421-432, 2004.
[10] D. Algar and R. Smith, “Approaching Eden," Landscape, vol. 13, pp. 28-34, 1998.

[11] L. E. Twigg, G. R. Martin, and T. J. Lowe, "Evidence of pesticide resistance in medium-sized mammalian pests: a case study with 1080 poison and Australian rabbits," Journal of Applied Ecology, vol. 39, no. 4, pp. 549-560, 2002.

[12] D. A. Risbey, M. C. Calver, and J. Short, "The impact of cats and foxes on the small vertebrate fauna of Heirisson Prong, Western Australia. I. Exploring potential impact using diet analysis," Wildlife Research, vol. 26, no. 5, pp. 621-630, 1999.

[13] B. Catling and A. M. Reid, Predator and Critical Weight Range Species 5. Results of Spring 2002 and Autumn 2003 Surveys, CSIRO Sustainable Ecosystems, Canberra, Australia, 2003.

[14] D. A. Risbey, M. Calver, and J. Short, "Control of feral cats for nature conservation. I. Field tests of four baiting methods," Wildlife Research, vol. 24, no. 3, pp. 319-326, 1997.

[15] N. D. Burrows, D. Algar, A. D. Robinson, J. Sinagra, B. Ward, and G. Liddelow, "Controlling introduced predators in the Gibson Desert of Western Australia," Journal of Arid Environments, vol. 55, no. 4, pp. 691-713, 2003.

[16] D. Algar and N. D. Burrows, "Feral cat control research: Western Shield review-February 2003," Conservation Science Western Australia, vol. 5, no. 2, pp. 131-163, 2004.

[17] D. Hegglin, F. Bontadina, S. Gloor et al., "Baiting red foxes in an urban area: a camera trap study," Journal of Wildlife Management, vol. 68, no. 4, pp. 1010-1017, 2004.

[18] M. Olsson, E. Wapstra, G. Swan, E. Snaith, R. Clarke, and T. Madsen, "Effects of long-term fox baiting on species composition and abundance in an Australian lizard community," Austral Ecology, vol. 30, no. 8, pp. 899-905, 2005.

[19] D. Algar, G. J. Angus, M. R. Williams, and A. Mellican, "Influence of bait type, weather and prey abundance on bait uptake by feral cats (felis catus) on peron Peninsula, Western Australia," Conservation Science Western Australia, vol. 6, no. 1, pp. 109-149, 2007.

[20] K. E. Moseby, J. Stott, and H. Crisp, "Improving the effectiveness of poison baiting for the feral cat and European fox in northern South Australia: the influence of movement, habitat use and activity," Wildlife Research, vol. 36, pp. 1-14, 2009.

[21] E. A. Denny and C. R. Dickman, Review of Cat Ecology and Management Strategies in Australia, Invasive Animals Cooperative Research Centre, Canberra, Australia, 2010.

[22] F. Palomares and T. M. Caro, "Interspecific killing among mammalian carnivores," American Naturalist, vol. 153, no. 5, pp. 492-508, 1999.

[23] K. R. Crooks and M. E. Soulé, "Mesopredator release and avifaunal extinctions in a fragmented system," Nature, vol. 400, no. 6744, pp. 563-566, 1999.

[24] A. S. Glen and C. R. Dickman, "Complex interactions among mammalian carnivores in Australia, and their implications for wildlife management," Biological Reviews of the Cambridge Philosophical Society, vol. 80, no. 3, pp. 387-401, 2005.

[25] E. G. Ritchie and C. N. Johnson, "Predator interactions, mesopredator release and biodiversity conservation," Ecology Letters, vol. 12, no. 9, pp. 982-998, 2009.

[26] J. M. Goodrich and S. W. Buskirk, "Control of abundant native vertebrates for conservation of endangered species," Conservation Biology, vol. 9, no. 6, pp. 1357-1364, 1995.

[27] R. O. Peterson, "Wolves as interspecific competitors in canid ecology," in Ecology and Conservation of Wolves in a Changing World, L. N. Carbyn, Fritts , S.H., and D. R. Seip, Eds., pp. 315323, Alberta, Canada, Canadian Circumpolar Institute, 1995. 
[28] S. E. Henke and F. C. Bryant, "Effects of coyote removal on the faunal community in western Texas," Journal of Wildlife Management, vol. 63, no. 4, pp. 1066-1081, 1999.

[29] R. J. Hobbs, "Synergisms among habitat fragmentation, livestock grazing, and biotic invasions in southwestern Australia," Conservation Biology, vol. 15, no. 6, pp. 1522-1528, 2001.

[30] A. E. Newsome, "The biology and ecology of the dingo," in A Symposium on the Dingo, C. R. Dickman and D. Lunney, Eds., pp. 20-23, Royal Zoological Society of New South Wales, Sydney, Australia, 2001.

[31] A. E. Newsome, P. C. Catling, B. D. Cooke, and R. Smyth, "Two ecological universes separated by the dingo barrier fence in semi-arid Australia: interactions between landscapes, herbivory and carnivory, with and without dingoes," Rangeland Journal, vol. 23, no. 1, pp. 71-98, 2001.

[32] M. J. Daniels and L. Corbett, "Redefining introgressed protected mammals: when is a wildcat a wild cat and a dingo a wild dog?" Wildlife Research, vol. 30, no. 3, pp. 213-218, 2003.

[33] M. Letnic, F. Koch, C. Gordon, M. S. Crowther, and C. R. Dickman, "Keystone effects of an alien top-predator stem extinctions of native mammals," Proceedings of the Royal Society B, vol. 276, no. 1671, pp. 3249-3256, 2009.

[34] M. Letnic, M. S. Crowther, and F. Koch, "Does a top-predator provide an endangered rodent with refuge from an invasive mesopredator?" Animal Conservation, vol. 12, no. 4, pp. 302312, 2009.

[35] N. G. Hairston, F. E. Smith, and L. B. Slobodkin, "Community structure, population control, and competition," American Naturalist, vol. 95, pp. 421-425, 1960.

[36] A. R. Pople, G. C. Grigg, S. C. Cairns, L. A. Beard, and P. Alexander, "Trends in the numbers of red kangaroos and emus on either side of the South Australian dingo fence: evidence for predator regulation?" Wildlife Research, vol. 27, no. 3, pp. 269 276, 2000.

[37] B. D. Mitchell and P. B. Banks, "Do wild dogs exclude foxes? Evidence for competition from dietary and spatial overlaps," Austral Ecology, vol. 30, no. 5, pp. 581-591, 2005.

[38] A. D. Wallach, C. N. Johnson, E. G. Ritchie, and A. J. O’Neill, "Predator control promotes invasive dominated ecological states," Ecology Letters, vol. 13, no. 8, pp. 1008-1012, 2010.

[39] P. Marsack and G. Campbell, "Feeding behaviour and diet of dingoes in the Nullarbor Region, Western Australia," Australian Wildlife Research, vol. 17, no. 4, pp. 349-357, 1990.

[40] R. Palmer, Feral Pest Program Project 12, Cat Research and Management in Queensland, year 4; and Project 43. Dispersal and Spatial Organisation of Cats on the Diamantina Plains, year 3, Interim Final Report to the Feral Pests Program, Australian Nature Conservation Agency, Canberra, Australia, 1996.

[41] P. Fleming, L. Corbett, R. Harden, and P. Thomson, Managing the Impacts of Dingoes and other Wild Dogs, Bureau of Rural Sciences, Canberra, Australia, 2001.

[42] D. Lunney, B. Triggs, P. Eby, and E. Ashby, "Analysis of scats of dogs Canis familiaris and foxes Vulpes vulpes (Canidae: Carnivora) in coastal forests near Bega, New South Wales," Australian Wildlife Research, vol. 17, no. 1, pp. 61-68, 1990.

[43] P. C. Thomson, "The behavioural ecology of dingoes in northwestern Australia. III. Hunting and feeding behaviour, and diet," Wildlife Research, vol. 19, no. 5, pp. 531-541, 1992.

[44] L. Corbett, The Dingo in Australia and Asia, University of New South Wales Press, Sydney, Australia, 1995.

[45] R. Paltridge, "The diets of cats, foxes and dingoes in relation to prey availability in the Tanami Desert, Northern Territory," Wildlife Research, vol. 29, no. 4, pp. 389-403, 2002.
[46] C. N. Johnson and J. Vanderwal, "Evidence that dingoes limit abundance of a mesopredator in eastern Australian forests," Journal of Applied Ecology, vol. 46, no. 3, pp. 641-646, 2009.

[47] K. E. Moseby and J. L. Read, "The efficacy of feral cat, fox and rabbit exclusion fence designs for threatened species protection," Biological Conservation, vol. 127, no. 4, pp. 429437, 2006.

[48] J. Read, "Recruitment characteristics of the white cypress pine (Callitris glaucophylla) in arid South Australia," The Rangeland Journal, vol. 17, no. 2, pp. 228-240, 1995.

[49] K. E. Moseby, B. M. Hill, and J. L. Read, "Arid Recovery-A comparison of reptile and small mammal populations inside and outside a large rabbit, cat and fox-proof exclosure in arid South Australia," Austral Ecology, vol. 34, no. 2, pp. 156-169, 2009.

[50] R. Paltridge, D. Gibson, and G. Edwards, "Diet of the feral cat (Felis catus) in Central Australia," Wildlife Research, vol. 24, no. 1, pp. 67-76, 1997.

[51] R. Molsher, A. Newsome, and C. Dickman, "Feeding ecology and population dynamics of the fetal cat (Felis catus) in relation to the availability of prey in central-eastern New South Wales," Wildlife Research, vol. 26, no. 5, pp. 593-607, 1999.

[52] J. O. Helldin, O. Liberg, and G. Glöersen, "Lynx (Lynx lynx) killing red foxes (Vulpes vulpes) in boreal Sweden-Frequency and population effects," Journal of Zoology, vol. 270, no. 4, pp. 657-663, 2006.

[53] J. G. MacCracken, "Coyote food in a Southern California suburb," Wildlife Society Bulletin, vol. 10, pp. 280-281, 1982.

[54] E. S. Shargo, Home range, movement, and activity patterns of coyotes (Canis latrans) in Los Angeles suburbs, Ph.D. thesis, University of California, Los Angeles, Calif, USA, 1988.

[55] T. Quinn, "Coyote (Canis latrans) food habits in three urban habitat types of Western Washington," Northwest Science, vol. 71, no. 1, pp. 1-5, 1997.

[56] G. P. Edwards, N. De Preu, B. J. Shakeshaft, I. V. Crealy, and R. M. Paltridge, "Home range and movements of male feral cats (Felis catus) in a semiarid woodland environment in central Australia," Austral Ecology, vol. 26, no. 1, pp. 93-101, 2001.

[57] N. J. Marlow, P. C. Thomson, D. Algar, K. Rose, N. E. Kok, and J. A. Sinagra, "Demographic characteristics and social organisation of a population of red foxes in a rangeland area in Western Australia," Wildlife Research, vol. 27, no. 5, pp. 457464, 2000.

[58] J. Read and Z. Bowen, "Population dynamics, diet and aspects of the biology of feral cats and foxes in arid South Australia," Wildlife Research, vol. 28, no. 2, pp. 195-203, 2001.

[59] S. R. Eldridge, B. J. Shakeshaft, and T. J. Nano, "The impact of wild dog control on cattle, native and introduced herbivores and introduced predators in central Australia," Final Scientific Report to Bureau of Rural Sciences, Northern Territory, Australia, 2002.

[60] P. C. Thomson, "The behavioural ecology of dingoes in northwestern Australia. IV. Social and spatial organisation, and movements," Wildlife Research, vol. 19, no. 5, pp. 543-563, 1992.

[61] A. D. Wallach, E. G. Ritchie, J. Read, and A. J. O’Neill, “More than mere numbers: the impact of lethal control on the social stability of a top-order predator," PLoS One, vol. 4, no. 9, Article ID e6861, 2009.

[62] S. E. Grubbs and P. R. Krausman, "Observations of coyote-cat interactions," Journal of Wildlife Management, vol. 73, no. 5, pp. 683-685, 2009. 
[63] L. K. Corbett and A. E. Newsome, "The feeding ecology of the dingo-III. Dietary relationships with widely fluctuating prey populations in arid Australia: an hypothesis of alternation of predation," Oecologia, vol. 74, no. 2, pp. 215-227, 1987.

[64] A. E. Newsome and B. J. Coman, "Canids," in Fauna of Australia. Mammalia, D. W. Walron and B. J. Richardson, Eds., vol. 1B, pp. 993-1005, Australian Government Publishing Service, Canberra, Australia, 1989.

[65] M. E. Soulé, J. A. Estes, B. Miller, and D. L. Honnold, "Strongly interacting species: conservation policy, management, and ethics," BioScience, vol. 55, no. 2, pp. 168-176, 2005.

[66] J. Short, J. E. Kinnear, and A. Robley, "Surplus killing by introduced predators in Australia-Evidence for ineffective anti-predator adaptations in native prey species?" Biological Conservation, vol. 103, no. 3, pp. 283-301, 2002.

[67] J. E. Kinnear, M. L. Onus, and R. N. Bromilow, "Fox control and rock-wallaby population dynamics," Australian Wildlife Research, vol. 15, no. 4, pp. 435-450, 1988.

[68] J. E. Kinnear, M. L. Onus, and N. R. Sumner, "Fox control and rock-wallaby population dynamics-II. An update," Wildlife Research, vol. 25, no. 1, pp. 81-88, 1998.

[69] S. R. Morton, "The impact of European settlement on the vertebrate animals of arid Australia: a conceptual model," Proceedings of the Ecological Society of Australia, vol. 16, pp. 201213, 1990. 

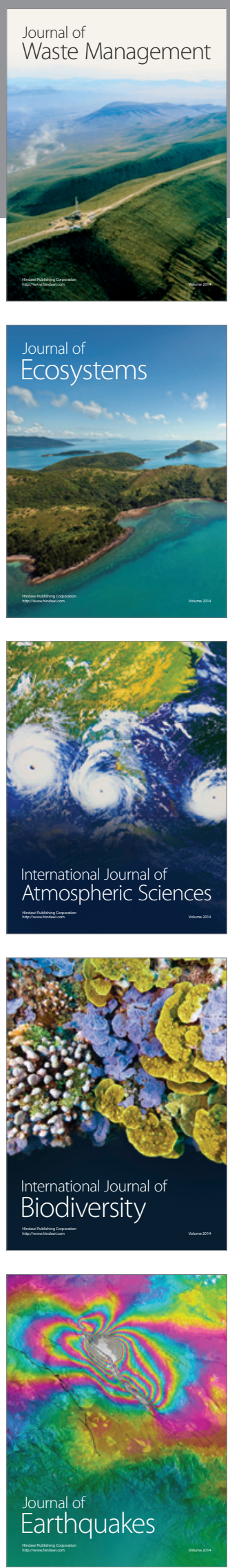
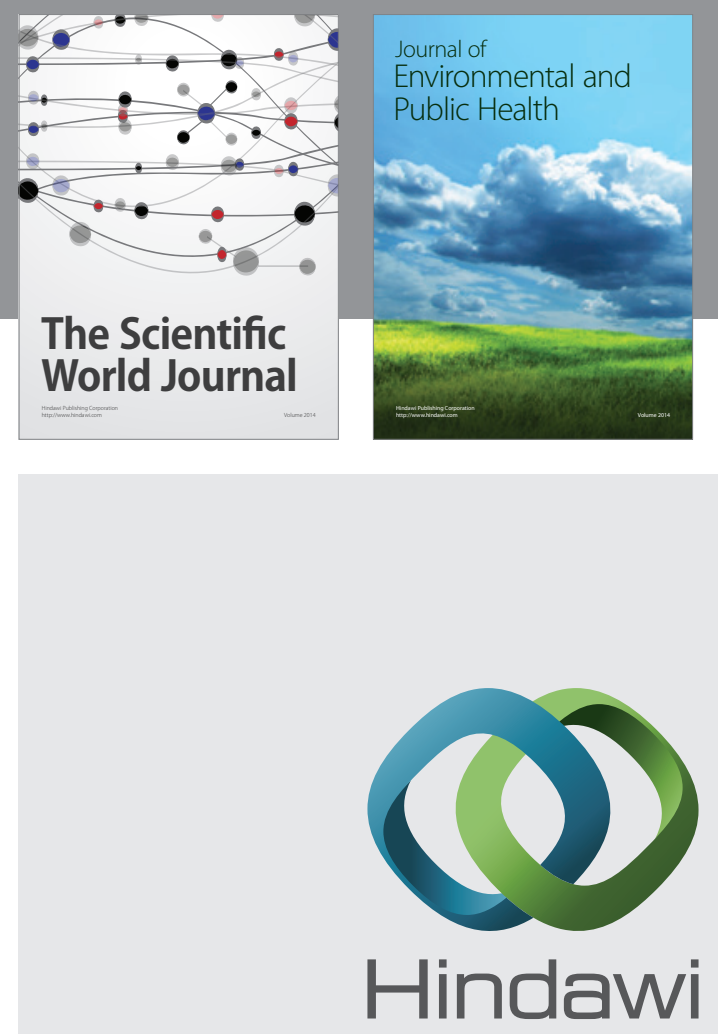

Submit your manuscripts at

http://www.hindawi.com
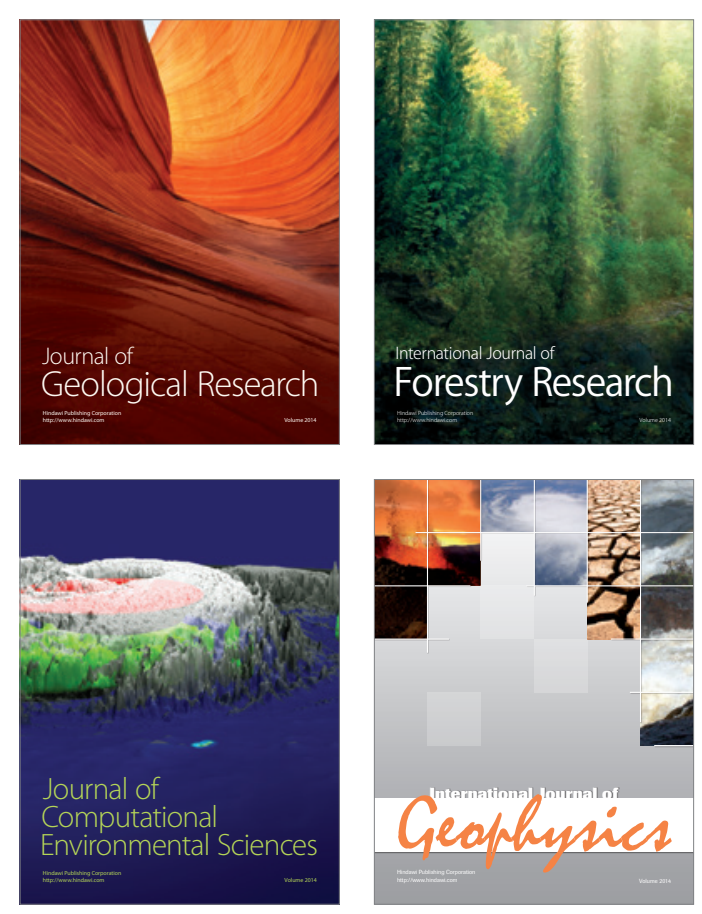
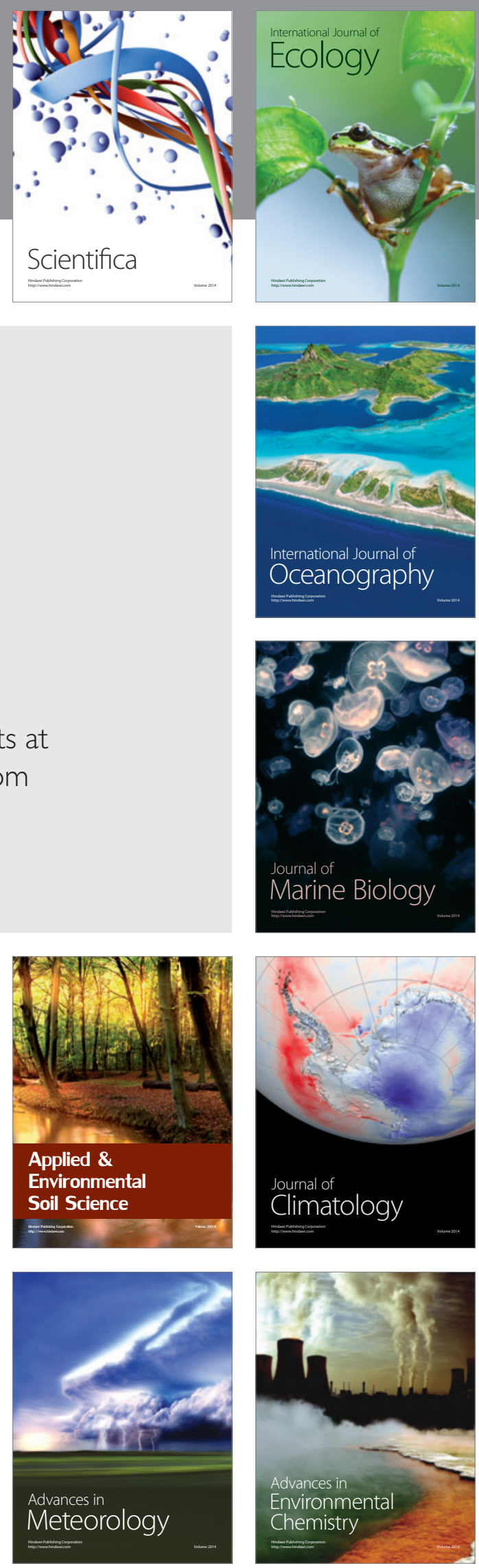